\title{
USING NARRATIVE ENQUIRY TO INVESTIGATE THE DEVELOPMENT OF STUDENTS' ENGINEERING IDENTITY IN A DEGREE APPRENTICESHIP
}

\author{
Elena LIQUETE, Professor Gina WISKER and Dr Elies DEKONINCK \\ University of Bath
}

\begin{abstract}
Every year, around $35 \%$ of engineering graduates (mainly female and ethnic minority graduates) in the UK choose roles outside engineering (EngineeringUK 2019) [1]. Given that engineering as a profession struggles to attract recruits, this represents a significant loss of qualified talent the profession can ill afford. A possible reason why engineers choose not to practise after qualifying may be that they have not developed a professional engineering identity during their engineering education. Eliot and Turns (2011) [2] define professional identity as "personal identification with the duties, responsibilities, and knowledge associated with a professional role". Engineering identity is the extent to which students identify themselves as engineers. Research shows that engineering identity is an important indicator of persistence in both engineering education and the engineering profession (Godwin, 2016) [3] (Beam et al 2009) [4] (Cech et al 2011) [5]. The purpose of this research is to find ways of reducing the number of engineers who graduate and then do not practise, by identifying ways in which they can better develop their engineering identity during their studies. The findings presented in this paper are surprising in that they seem to indicate that the four years of a degree apprenticeship have had little impact on students who already had either low or high identification with engineering. Engineering educators should consider how the development of an engineering identity can be supported in engineering degrees.
\end{abstract}

Keywords: Engineering identity, engineering education, identity theory, degree apprenticeships

\section{INTRODUCTION}

Education in the UK is devolved to its four nations, so this paper will focus on engineering education in England, where there are two routes to qualifying as an engineer: an academic route via a university degree and a work-based route via an apprenticeship degree. The students in this study are apprentices studying two days per week for a BEng in Engineering and working three days per week in engineering teams for a technology company. This research will explore how these students develop their engineering identity during the four years of their education and the impact of their engineering identity in how they envision their future - inside or outside engineering.

Identity theory provides a useful lens for the study of professional engineering identity. If we believe that "Identities are the meanings that individuals hold for themselves - "what it means to be who they are" (Burke, 2003) [6] then a methodology that uses the tools of social science to study personal meaning, narrative enquiry, seems well suited to the study of identity (Goodson \& Sikes 2001) [7]. This methodology is rarely used in engineering education (Foor, Walden \& Trytten, 2007, p. 104) [8]. This paper explores the identity theory literature, the use of narrative enquiry as a research method and findings from pilot trials.

\section{IDENTITY IN ENGINEERING EDUCATION}

Admissions processes for engineering programmes tend to focus on finding candidates who are good at sciences, mathematics, and physics in particular. However, the success of those candidates in the engineering profession is closely linked to their identities. Whilst formally all a student needs to become a professional is to graduate from the appropriate institution, as Costello's research shows, "a certified professional school graduate who cannot "walk the walk and talk the talk" will not seem like a true professional to others and will not be successful" (Costello, C.Y. 2005, p. 23) [9] Acquiring engineering knowledge and skills is clearly an important part in becoming an engineer but it is not enough; to become 
engineers, students must develop an engineering identity (Brickhouse et al, 2000) [10]. Many authors have looked at engineering identity, however, identity theory as a conceptual model has been largely overlooked. This article seeks to address that gap. Identity theory is rooted in the work of the American sociologist George Herbert Mead (1934) [11], who theorized that the self-arises from social interaction. Blumer (1962) [12] coined the term "symbolic interaction" to highlight that behaviours are symbols that carry meaning; what is important is not so much how we behave but how we and others interpret our behaviour. We operate within the structures in our society and our behaviour is shaped by those structures; this is what Stryker (1980) [13] means when he refers to "structural symbolic interactionism" (SSI). Those structures include class, gender, ethnicity, profession, etc.

Stryker and Burke (2000, p. 284) [14] define identity as "the meanings that persons attach to the multiple roles they typically play in highly differentiated contemporary societies". The basic premise of SSI is that identity emerges through interpersonal interaction and that these interactions are shaped by social structure; the social structure defines what behaviours are appropriate for each role. As we internalize those expectations, we are setting up the basis for our identity in that particular role. Stryker emphasized the role played by social structures in shaping human behaviour, recognizing the reciprocal nature of these relationships: "society shapes self, which shapes social interaction" (Stryker and Burke (2000, p. 231) [15]. He defines identity as the "internalized positional designation" linked to each role a person has in society (Stryker, 1980 (2002) p. 60) [16]. He understands those positions to be relatively stable and built into the structure of a given society. Individuals within a society label each other and themselves, according to the positions they occupy, i.e., teacher or student. As individuals internalize those identities, they also internalize the meanings and behaviours that are expected of those identities and occupy their position in the social structure as well as the symbols and shared perceptions associated to an identity, in this case engineering identity. For engineering students, this means embracing the personal characteristics associated with the engineering profession, such as a logical approach to problem solving, attention to detail and tough-mindedness for instance (Williamson et al, 2013) [17]. They must also be perceived as an engineer by their peers and colleagues.

A central premise in identity theory is that "people seek ways to establish and maintain those social situations and relationships in which their identities are verified." (Burke and Stets, 1999 p. 351) [18]. As engineering educators, we probably have a sense that this is the case and indeed, research shows that difficulties in verifying an engineering identity can cause students to abandon their studies (Pierrakos et al. 2009) [19] (Patrick, Borrego \& Prybutok 2018) [20]. Burke (2009) [21] proposes that identities operate as a continuous feedback loop, managing the meanings perceived in a given situation, with the objective of maintaining self-meaning within a comfortable range. When the perceived meaning (our interpretation of how others see us) matches our own self-meaning, our identities are verified. Identity verification leads to increased trust, commitment, and emotional attachment towards those who are verifying our identity and in turn, those feelings increase our sense of belonging to that particular group (Burke and Stets 1999. P 351) [22]. A person's identity becomes stronger when it is verified repeatedly. Lack of identity verification generates negative emotions linked to feelings of low self-esteem and low mastery (Cast and Burke, 2002) [23].

It would be too easy to assume that a student who does well in her engineering studies, obtaining good academic results, would have her engineering identity validated. However, grades may not be enough, as being an engineering student invokes more than one single identity. Identity theory proposes that there are three different types of identities: role, group, and person identities. Burke and Stets (2009, p. 114) [24] define role identity as "the internalized meaning of a role that individuals apply to themselves." As different people will internalize meaning in a different way, the same role identity may have different meanings for different individuals. This is clearly the case in engineering, as there is a lack of clarity as to what it means to be an engineer. Group identity relates to how individuals identify themselves with a social group, in this case the engineering profession and finally, person identity is "the set of meanings that define the person as a unique individual rather than as a role-holder or group member" (Burke and Stets 2009, p. 124) [25]. Going back to our engineering student, for her engineering identity to be validated she needs to see herself as an engineer, but she also needs others (the classmates, lecturers, colleagues in the workplace, etc.) to see her as one. When someone validates our identity, we respond by generating trust in that person and over time, this fosters greater commitment to the relationship (Burke and Stets, 1999) [26]. Identity verification of a role identity generates feelings of mastery and efficacy. Verification of a group identity generates feelings of self-esteem and integration (Burke and Stets, 1998) [27]. The discussion outlined above led the researcher to hypothesize that: 
Students with a strong engineering identity are more likely to have experienced trust in a formative relationship.

Students with a stronger engineering identity are more likely to be committed to a future in engineering.

\section{RESEARCH METHODOLOGY}

The researcher's interest in the study of identity led her to explore life stories as a possible methodology for this research. Narrative enquiry uses personal stories as data and particularly since the 1990s, has become a widely used methodology for "understanding the meaning of human experience" (Merriam and Tisdell, 2016, p. 34) [28] although as a research methodology, it has been rarely used in engineering education (Foor, Walden \& Trytten, 2007, p. 104) [29]. It is, however, particularly well suited to the study of identity (Goodson \& Sikes 2001) [30] as in retelling their stories, individuals are constructing their identities (Chaitin, 2004) [31]. Life story interviews allow individuals to tell their life story in their own way, charting the path that has taken them to where they are today. Those stories are not set in stone; as we tell our stories, we choose what is important at a given point in time, in a particular setting and with a specific audience. Narrative enquiry as a methodology offers a way of interpreting someone's experience (Atkinson 2012, p. 16) [32]. Following a narrative approach, semi structured interviews were conducted using a modified version of The Life Story Interview, an instrument developed by Dan McAdams (1995/2008) [33] at the Foley Centre for the Study of Lives at Northwestern University. In narrative research, the relationship between the researcher and the researched has epistemological implications that shape the way in which the research is conducted. The role of the researcher is particularly important because "the researcher is the instrument of both data collection and data interpretation" (Patton 1990, P. 54) [34].

Purposeful sampling was used to select research participants. Purposeful sampling is a technique widely used in qualitative research in which researchers select a sample "from which the most can be learnt" (Merriam \& Tisdell, 2016, p. 96) [35]. The researcher looked for participants who were willing to participate and were good communicators, as recommended by Palinkas (2015 p. 534) [36] who highlights the importance of selecting research participants who have "the ability to communicate experiences and opinions in an articulate, expressive, and reflective manner." Purposeful sampling requires in depth knowledge of the individual students to be selected. As the researcher did not personally know the students, she asked for help from the Student Support Advisor for each year group in order to identify students who they felt may be interested to contribute to this research. Out of the shortlist provided, one male and one female participant from years one and four of the degree apprenticeship were randomly selected for interview.

As an internal researcher i.e., employed by the institution in which this pilot study has been conducted, it is important to be aware of the "hidden ethical and methodological dilemmas of insiderness" (Labaree, 2002 , p. 109) [37]. Hammersley's view that "there are no overwhelming advantages to being an insider or an outsider. Each position has advantages and disadvantages, though these will take on slightly different weights depending on the particular circumstances and purposes of the research" (Hammersley, 1993, p. 219) [38] seems particularly relevant.

\section{DATA COLLECTION AND ANALYSIS}

The Covid-19 pandemic and subsequent lockdowns and restrictions in England meant that interviews had to be conducted using MS Teams rather than in person. Research on the use of computer mediated interviews seems to indicate that they can be a "viable alternative to the face-to-face interview" (Curasi 2001, p. 372) [39] and the researcher feels confident that this research has not suffered as a result of having to conduct interviews online. What is harder to predict, however, is the impact that online teaching during the pandemic, and therefore reduced levels of personal interaction with classmates and faculty, may have on the development of engineering identity for the class of 2020 and this is something that may need to be revisited in this research. Four ninety-minute interviews with students enrolled on the same engineering degree apprenticeship in England were conducted; two were in their first year and two in their fourth and final year. In each year group, one student was male, and one was female. Each video interview generated around seventeen pages of interview transcripts. Transcripts were analysed manually, reading them several times, seeking to reduce the data inductively, looking for themes in the different stories. Three out of the four undergraduates identified themselves with the engineering profession and saw their future as engineers; the fourth student was not so sure. Contrary to what may have been expected, the students with a strong engineering identity already had it by the time they started 
their apprenticeship and the nearly four years of their degree apprenticeship, offering exposure to an engineering workplace as well as academic study, had only served to clarify in the students' mind what aspects of engineering they enjoyed more than others. The fourth student started her engineering studies unsure about engineering as a career and remained unsured as the end of the degree apprenticeship loomed: "I' $m$ kind of currently at the stage where I am deciding whether to stay... in engineering or whether to just change completely, going to like investment banking". The three students who identified themselves with engineering had attended different schools in different parts of the country, came from different socioeconomic backgrounds and had different interests. However, their stories had one thing in common: all three had built trusted relationships with an adult whilst at school (a teacher in two cases, a scholarship mentor in the third) who had encouraged them to consider engineering as a profession before they had thought about it themselves. A first-year student said: "The (scholarship) mentor pushed me to apply, despite my response being that I was convinced maths was for me and that I was really unsure about engineering. He told me that strong mathematicians that loved problem solving were exactly what they were looking for and that getting the scholarship could open a wide array of opportunities for me. He convinced me that there was nothing to lose ... I'm definitely indebted to him for doing so, I wouldn't have had that platform for industry connections and insights. Without that I think I would really have struggled to break down the misconceptions that I had of engineering." For another student, it as a teacher: "My DT teacher... I spent an immense amount of time with him... and I started getting recognized within the classroom as the DT guy that everybody came to for...". A yearfour student commented: "My physics teacher, ..., he kind of pushed me a little bit more towards engineering. And that's when I flipped from physics to mechanical engineering". Through those relationships, the students had been encouraged to push their boundaries and go beyond their academic curriculum, and this resulted in the three students having more or less formal teaching roles with their peers and, in one case, students at other colleges. These activities can be interpreted as a form of Peer Assisted Learning, defined as "the acquisition of knowledge and skill through active help and support among status equals" which has been found to enhance cooperative learning and communication skills as well as improving the student's understanding of the subject under study (Gazula et al, 2017) [40]. By seeing their potential and encouraging them to do more, those adults had validated the students' identity and by trusting them with additional responsibility, they had reinforced that identity. According to identity theory, the validation of role and group identities generate different results: whist doing well in a class would generate feelings of self-efficacy, helping others to learn would also have a positive impact on the students' self-esteem. As the students had opportunities to do more of this, a positive feedback loop was established that lead to greater trust and commitment. One of the students in the first year often referred to herself and to her classmates as engineers: "sitting down in the kitchen with five other engineers I've never met before of my age and immediately you just have that 'click'." In contrast, despite being close to graduation, the fourth-year student who did not identify with engineering, never referred to herself as an engineer during the interview: "I know I can do engineering and I can be an engineer ... it's just not necessarily where I see myself going 100\%".

\section{CONCLUSIONS}

Degree apprenticeships expose students to academic learning in engineering disciplines and give them the opportunity to work in an engineering setting for the four years of the program, engaging students in multiple projects and working with different engineering teams. It would be reasonable to expect that such exposure would have an impact on the engineering identity of degree apprentices. However, this pilot study seems to indicate that may not be the case and that students' engineering identity was already set by the time they started their degree apprenticeship. The students interviewed who arrived with a strong engineering identity maintained it and the one who did not, failed to develop it. The findings of this pilot study seem to confirm the two hypothesis I outlined above, highlighting the importance of relationships with teachers and mentors in fostering an engineering identity. The findings also seem to confirm that students with a strong engineering identity see their future in engineering. These findings would suggest that engineering educators need to build opportunities for students to validate their engineering identities into their programs. This can be achieved by getting to know their students better and developing closer relationships with them and by creating opportunities for students to get involved in Peer Assisted Learning. Supportive personal relationships in an engineering setting develop trust which in turn develops commitment towards engineering as a profession. These are the findings of a pilot study that focused on degree apprentices. This research will be expanded by include students 
enrolled on a conventional engineering degree at a university in England, and to conduct a larger number of interviews with both cohorts of university students and degree apprentices. The larger sample will also enable further comparison between the early and later year students. The openness showed by the students who participated in the pilot study and the depth of the insights they shared begins to throw new light into this fascinating topic.

\section{REFERENCES}

[1] EngineeringUK, Key facts \& figures. Highlights from the 2019 update to the Engineering UK report. Available at: https://www.engineeringuk.com/media/156198/key-facts-figures-2019-final20190627.pdf [Accessed on 2021, 10 January]

[2] Eliot M. and Turns J. 2011. Constructing professional portfolios: sense-making and professional identity development for engineering undergraduates. Journal of Engineering Education, Vol. 100, No. 4, pp. 630-654.

[3] Godwin A. 2016. The Development of a measure of engineering identity. ASEE's 123rd Annual Conference\& Exposition. New Orleans, LA, p. 1.

[4] Beam T. K., Pierrakos O., Constantz J. Johri A. and Anderson R. 2009. Preliminary findings on freshmen engineering students' professional identity: implications for recruitment and retention. ASEE Annual Conference \& Exposition. Austin. TX.

[5] Cech E. Rubineau B. Silvey S. and Seron C. 2011. Professional role confidence and gendered persistence in engineering. American Sociological Review, 76(5), pp. 641-666.

[6] Burke P. J. 2003. Relationships among multiple identities. Pp. 195-216 in Advances in Identity Theory and Research, edited by Peter J. Burke, Timothy J. Owens, Richard T. Serpe, and Peggy A. Thoits, New York: Kluwer.

[7] Goodson I. and Sikes P. 2001. Life History Research in Educational Settings: Learning from Lives. Open University Press, Buckingham.

[8] Foor C. E. Walden S. E. and Trytten D. A. 2007. "I wish that I belonged more in this whole engineering group:" Achieving individual diversity. Journal of Engineering Education. Vol 96, Issue 2. Pp. 103-115.

[9] Costello C. G. [published under Costello, Carrie Yang] 2005. Professional Identity Crisis. Race, class, gender, and success at professional schools. Vanderbilt University Press. Nashville, Tennessee.

[10] Brickhouse N. W., Lowery P., and Schultz K. 2000. What kind of a girl does science? The construction of school science identities. Journal of Research in Science Teaching. Vol.37 (5), p.441-458.

[11] Mead G. H. 1934. Mind, self, and society. Chicago: University of Chicago Press.

[12] Blumer H. 1963. Society as symbolic interaction. In Human behaviour and social processes, edited by A. M. Rose. Boston. Houghton Mifflin.

[13] Stryker S. 1980. Symbolic interactionism: a social structural version. Menlo Park, CA/Cadwell NJ.

[14] Stryker S. and Burke P. J. 2000. The Past, Present, and Future of an Identity Theory. Social Psychology Quarterly 63(4) pp. 284-297

[15] IBID.

[16] Stryker S. 1980. (2002) Symbolic Interactionism: A social structural version. Caldwell, NJ. Blackburn Press.

[17] Williamson J. M., Lounsbury J. W., and Han L. D. 2013. Key personality traits of engineers for innovation and technology development, Journal of Engineering and Technology Management, Volume 30, Issue 2.

[18] Burke P. J. and Stets J. E. 1999. Trust and commitment through self-verification. Social Psychology Quarterly, 62. Pp. 347-66

[19] Beam T. K., Pierrakos O., Constantz J. Johri A. and Anderson R. 2009. Preliminary findings on freshmen engineering students' professional identity: implications for recruitment and retention. ASEE Annual Conference \& Exposition. Austin. TX.

[20] Patrick A. Borrego M. and Prybutok A. 2018. Predicting persistence in engineering through an engineering identity scale. International. Journal of Engineering Education, 34(2(A)), Pp. 351363.

[21] Burke P. J and Stets J. E. 2009. Identity Theory. New York: Oxford University Press. 
[22] IBID.

[23] Cast A. D and Burke P. J. 2002. A theory of self-esteem. Social Forces 80, Pp. 1041-68

[24] Burke P. J. and Stets J. E. 2009. Identity Theory. New York: Oxford University Press.

[25] IBID.

[26] IBID.

[27] IBID.

[28] Merriam S. B and Tisdell E. J. 2016. Qualitative Research. A guide to design and implementation. 4th Edition. Jossey-Bass.

[29] Foor C. E., Walden S. E., and Trytten D. A. (2007), "I wish that I belonged more in this whole engineering group:" Achieving individual diversity. Journal of Engineering Education, 96, pp. 103-115.

[30] Goodson I. and Sikes P. 2001. Life History Research in Educational Settings: Learning from Lives. Open University Press, Buckingham.

[31] Chaitin J. 2004. My Story, my life, my identity. International Journal of Qualitative Methods (Online) 3 - 4. Available from: https://journals.sagepub.com/doi/pdf/10.1177/160940690400300401 (Accessed: 2021, 10 January)

[32] Atkinson R. 2012. The life story interview as a bridge in narrative inquiry. In Clandinin, J. Ed. Handbook of narrative inquiry: mapping a methodology. Thousand Oaks. Sage Publications

[33] McAdams D. P. 2008. The life story interview. Available from: https://www.sesp.northwestern.edu/foley/instruments/interview (Accessed: 2021, 15 January)

[34] Patton M. Q. 1990. Qualitative evaluation and research methods. Second Edition. Thousand Oaks. Sage [27] Curasi, C.F. 2001. A critical exploration of face-to-face interviewing vs. computer-mediated interviewing. International journal of market research vol 43 Quarter 4.

[35] Merriam S. B. and Tisdell E. J. 2016. Qualitative Research. A guide to design and implementation. 4th Edition. Jossey-Bass

[36] Palinkas L.A., Horwitz S. M., Green C. A. et al. 2015. Purposeful Sampling for Qualitative Data Collection and Analysis in Mixed Method Implementation Research. Adm Policy Ment Health $42,533-544$.

[37] Labaree R. V. 2002. The risk of 'going observationalist': negotiating the hidden dilemmas of being an insider participant observer. Qualitative Research, 2(1), pp. 97-122.

[38] Hammersley M. 1993. On the teacher as researcher, in: M. Hammersley Ed. Educational research: volume one; current issues. London, Paul Chapman/The Open University.

[39] Curasi C. F. 2001. A critical exploration of face-to-face interviewing vs. computer-mediated interviewing. International journal of market research. Vol 43 Quarter 4.

[40] Gazula S., McKenna L., Cooper S., and Paliadelis P. 2017. A Systematic Review of Reciprocal Peer Tutoring within Tertiary Health Profession Educational Programs, Health Professions Education, Volume 3, Issue 2. 